\title{
The Inhibitory Effect of Gut Microbiota and Its Metabolites on Colorectal Cancer
}

\author{
Chao Chen ${ }^{1}$ and Huajun $\mathrm{Li}^{2 *}$ \\ 'Department of Colorectal Surgery, the Second Affiliated Hospital, Zhejiang University School of Medicine, \\ Hangzhou 310000, Zhejiang Province, P.R. China \\ ${ }^{2}$ Department of Microecology, College of Basic Medical Sciences, Dalian Medical University, Dalian, Liaoning \\ 116044 , P.R. China
}

\begin{abstract}
Colorectal cancer (CRC) is regarded as one of the most common and deadly forms of cancer. Gut microbiota is vital to retain and promote several functions of intestinal. Although previous researches have shown that some gut microbiota have the abilities to inhibit tumorigenesis and prevent cancer from progressing, they have not yet clearly identified associative mechanisms. This review not only concentrates on the antitumor effects of metabolites produced by gut microbiota, for example, SCFA, ferrichrome, urolithins, equol and conjugated linoleic acids, but also the molecules which constituted the bacterial cell wall have the antitumor effect in the host, including lipopolysaccharide, lipoteichoic acid, $\beta$-glucans and peptidoglycan. The aim of our review is to develop a possible therapeutic method, which use the products of gut microbiota metabolism or gut microbiota constituents to help treat or prevent colorectal cancer.
\end{abstract}

Keywords: Gut microbiota, gut microbial metabolites, bacteria components, colorectal cancer, anticancer effect

\section{Introduction}

CRC is the second leading cause of cancer-related death worldwide. There are about 700,000 people dying of CRC every year [1]. CRC is considered as one of the health care challenges, and it is related to genetic encoding and more significantly, about 70\% of all CRC cases are influential by environmental aspects through a couple of years, including diets, lifestyle, metabolic syndrome and gut microecology, etc [2].

Gut microbiota consists mainly of bacteria, fungi, bacteria and viruses that populate the gut, primarily the large intestine. About $90 \%$ of gut microbiota is composed of two phyla, that is, Firmicutes and Bacteroidetes, in healthy human [3]. With the development of technology, we have a better understanding of the composition, function and metabolic characteristics of the human gut microbiota [4]. There is growing evidence that commensal bacteria of human being is the vital determinant of healthy or pathological conditions, including cancer [5]. Metagenomics and metabolomics researches stressed the double effect of the gut microbiota in tumorigenesis (either inhibit cancer or promote cancer) [6]. Gut microbiota exerts the significant effects on host by producing vitamins, metabolizing dietary compounds, inhibiting the expansion and systemic infiltration of gut pathogens [7]. Other results underline the complicacy and two-way of the association between microbiota and cancer. The progression of cancer may change the microbiota. Meanwhile, altering microbiota may influence cancer development [8].

Received: February 17, 2020 Accepted: May 31, 2020

First published online: June 4,2020

*Corresponding author Phone: +86-411-86110305 Fax: +86-411-86110305 E-mail: Ihjcmu@hotmail.com

pISSN 1017-7825 elSSN 1738-8872

Copyright@ 2020 by The Korean Society for Microbiology and Biotechnology
Undoubtedly, the occurrence of CRC is also related to the function of some gut microbiota constituents whose role serves as initiator or inhibitor [9].

Although we have studied the association for many years, only a small part feature was exposed. In this essay, we will list some current results about cellular and microbial metabolism regulation in CRC, concentrating on the mechanistic association of gut microbiota metabolites and constituents with CRC prevention or treatment.

\section{The Mechanism of Gut Microbiota against Cancer}

Recently evidences from in vitro and animal model to clinical trials, as well as the use of selected gut microbiota for preventing or treating CRC, have demonstrated the antiproliferative activity. The selected gut microbiota mainly includes Lactobacillus, Bifidobacterium sp., Enterococcus faecalis and so on. Many studies based on human cancer cells or cell line demonstrated that gut microbiota processes the function of restraining cell proliferation or stimulating apoptosis in CRC (Table 1). In the main animal models studied from 2017 to 2019, N-methyl-Nnitrosourea (MNU), 1,2-dimethylhydrazine (DMH) and azoxymethane (AOM) were used as CRC inductor respectively. The specific gut microbiota studied in these models is shown in Table 2. In human studies conducted between 2015 and 2017, several double-blind, randomized and placebo controlled researches indicated that the addition of specific gut microbiota is effective in treating, which reduces the postoperative complications of CRC 
Table 1. Potential anticancer effect of gut microbiota on CRC cells.

\begin{tabular}{|c|c|c|c|}
\hline Probiotic strain & Cells & Result & Ref. \\
\hline Lactobacillus helveticus NS8 & HT-29; SW480; Caco-2 & The viability of HT-29 and SW480 cells $\downarrow$ & [60] \\
\hline $\begin{array}{l}\text { Lactobacillus paracasei IMPC } 2.1 \\
\text { Lactobacillus rhamnosus ATCC } \\
53103 \text { (L. GG) }\end{array}$ & HGC-27; DLD-1 & $\begin{array}{l}\text { Growth } \downarrow \\
\text { Apoptosis } \uparrow\end{array}$ & [29] \\
\hline $\begin{array}{l}\text { Lactobacillus kefri } \mathrm{P}-\mathrm{IF} \\
\text { Lactobacillus kefri } \mathrm{P}-\mathrm{B} 1 \\
\text { Kazachstaniaturicensis, } \\
\text { Kazachstaniaunispora } \\
\text { Kluyveromycesmarxianus }\end{array}$ & $\begin{array}{l}\text { Human multidrugresistant (MDR) } \\
\text { myeloid leukemia (HL60/AR) cells }\end{array}$ & Apoptotic $\uparrow$ & [61] \\
\hline Enterococcus lactis IW5 & HeLa; MCF-7; AGS; HT-29; Caco-2 & $\begin{array}{l}\text { Apoptosis } \uparrow \\
\text { Extrinsic IL-3 receptor pathway }\end{array}$ & {$[62]$} \\
\hline $\begin{array}{l}\text { Lactobacillus rhamnosus } \\
\text { strain GG (L. GG) }\end{array}$ & HGC-27; DLD-1 & Proliferation $\downarrow$ & [63] \\
\hline
\end{tabular}

Table 2. Potential anticancer effect of gut microbiota on animal model.

\begin{tabular}{|c|c|c|c|c|}
\hline Probiotic strain & Animal model & $\begin{array}{l}\text { Induced colon } \\
\text { cancer } \\
\text { (carcinogen) }\end{array}$ & Reported effect & Ref. \\
\hline Lactobacilluscasei BL23 & C57BL6 mice. & $\mathrm{AOM}$ & $\begin{array}{l}\text { Protected mice against CRC development; } \\
\text { IL- } 22 \text { cytokine } \downarrow \\
\text { Caspase-7, caspase-9, and Bik } \uparrow\end{array}$ & {$[24]$} \\
\hline $\begin{array}{l}\text { Lactobacillus helveticus } \\
\text { NS8 }\end{array}$ & $\begin{array}{l}\text { C57BL/6 mice, } \\
\text { (males, } 4-5 \text { weeks old). }\end{array}$ & $\mathrm{AOM}+\mathrm{DSS}$ & $\begin{array}{l}\text { Tumour number } \downarrow \\
\text { The degree of hyperplasia } \downarrow \\
\text { NF- } \kappa \mathrm{B} \downarrow \\
\text { IL-10 } \uparrow \\
\text { IL-17-producing T cells } \downarrow\end{array}$ & [60] \\
\hline $\begin{array}{l}\text { Lactobacillus acidophilus } \\
\text { Bifidobacteriumanimalis } \\
\text { subsp. lactis }\end{array}$ & F344 rats (males) & $\mathrm{AOM}+\mathrm{DSS}$ & $\begin{array}{l}\text { Colorectal carcinogenesis } \downarrow \\
\text { Enhancing antioxidative capacity } \uparrow \\
\text { Apoptosis } \uparrow\end{array}$ & [64] \\
\hline $\begin{array}{l}\text { Enterococcus faecalis } \\
\text { strain } \mathrm{KH} 2\end{array}$ & C57BL/6 mice & $\mathrm{AOM}+\mathrm{DSS}$ & $\begin{array}{l}\text { DSS-induced murine experimental } \\
\text { Colitis } \downarrow \text { colitis-associated CRC } \downarrow\end{array}$ & [65] \\
\hline L. acidophilus B. bifidum & $\mathrm{BALB} / \mathrm{c}$ mice 6 week - old & $\mathrm{AOM}$ & Tumor suppressor miRNAs $\uparrow$ CRC $\downarrow$ & [66] \\
\hline
\end{tabular}

(Table 3). Although these studies have provided some positive feedback, the accurate molecular mechanisms of gut microbiota in preventing, curing, and inhibiting development of cancer are still at the beginning and need further elucidations. Through the literatures reviewed, we found that gut microbiota can not only prevent cancer but also treat cancer probably by: (1) Increasing the integrity of the epithelial barrier. (2) Promoting intestinal mucous membrane adhesion, and inhibiting pathogenic bacteria adhesion. (3) Eliminating pathogens in the intestinal barrier. (4) Producing anti-microorganism substances. (5) Modulating dendritic cells (DC), affecting the polarity of $\mathrm{T}$ cells, regulating the immune system and inflammation.

Table 3. Potential anticancer effect of gut microbiota on human.

\begin{tabular}{|c|c|c|c|}
\hline Probiotic strain & Patients & Reported effect & Ref. \\
\hline $\begin{array}{l}\text { Enterococcus faecalis } \mathrm{T} 110 \\
\text { Clostridium butyricum TO-A } \\
\text { Bacillus mesentericus TO-A }\end{array}$ & $\begin{array}{l}75 \text { patients: probiotic } \\
81 \text { patients: placebo } \\
3-15 \text { days before and the same day } \\
\text { after CRC resection operation }\end{array}$ & $\begin{array}{l}\text { Superficial incisional surgical site } \\
\text { infections (SSIs) } \downarrow \\
\text { Immune responses } \uparrow \\
\text { Intestinal microbial environment } \uparrow\end{array}$ & [67] \\
\hline $\begin{array}{l}\text { Pediococcuspentosaceus 5-33:3 } \\
\text { Leuconostocmesenteroides 32-77:1 } \\
\text { Lactobacillus paracasei ssp. paracasei } 19 \\
\text { Lactobacillus plantarum } 2362\end{array}$ & $\begin{array}{l}38 \text { patients: probiotic } \\
37 \text { patients: placebo } \\
\text { The intervention period lasted } 15 \\
\text { days before surgery }\end{array}$ & $\begin{array}{l}\text { GIQLI “Global score" } \uparrow \\
\text { Postcolectomy gastrointestinal } \\
\text { function } \uparrow\end{array}$ & [68] \\
\hline Saccharomyces boulardii & $\begin{array}{l}15 \text { patients: probiotic } \\
18 \text { patients: conventional treatment } \\
7 \text { days before surgery and was } \\
\text { interrupted on the operation day }\end{array}$ & $\begin{array}{l}\text { Mucosal IL-1 } \beta \text {, IL-10, and IL-23A } \\
\text { mRNA levels } \downarrow \\
\text { Both pro-and anti-inflammatory } \\
\text { cytokines } \downarrow\end{array}$ & [69] \\
\hline $\begin{array}{l}\text { Bifidobacterium lactis Bl-04 } \\
\text { Lactobacillus acidophilus NCFM }\end{array}$ & $\begin{array}{l}8 \text { patients: probiotic } \\
7 \text { patients: placebo } \\
\text { two daily tablets before surgery }\end{array}$ & $\begin{array}{l}\text { Microbial diversity } \uparrow \\
\text { Butyrate-producing bacteria } \uparrow \\
\text { CRC-associated genera } \downarrow\end{array}$ & [70] \\
\hline $\begin{array}{l}\text { Lactobacillus acidophilus NCFM } \\
\text { Lactobacillus rhamnosus HN001 } \\
\text { Lactobacillus paracasei LPC-37 } \\
\text { Bifidobacterium lactis HN019 }\end{array}$ & $\begin{array}{l}49 \text { patients: probiotic } \\
42 \text { patients: placebo } \\
5 \text { days before and } 14 \text { days after } \\
\text { surgery }\end{array}$ & Postoperative infection rates $\downarrow$ & [71] \\
\hline
\end{tabular}




\section{Gut Microbiota Metabolites}

\section{Short Chain Fatty Acids (SCFAs)}

Fiber is an important nutrient in diet. Dietary fiber is formed from undigested food components in plant cell walls, including non-starch polysaccharides, oligosaccharides, lignin, and analogous polysaccharides. Dietary fiber is the substrate of anaerobic fermentation of gut microbiota [10]. The majority of cellulose presented in the diet are broken into SCFAs, mainly acetate, propionate and butyrate [11]. The significant mechanisms of SCFAs influencing CRC may include: anti-inflammation and anti-proliferation.

Butyrate. To date, butyrate is the most widely studied of SCFAs. Butyrate is mainly produced by Coprococcus comes, Anaerostipes spp., Eubacteriumrectale, Faecalibacteriumprausnitzii, Roseburia spp. [12]. Butyrate is constituted by two molecules of acetyl-CoA, yielding acetoacetyl-CoA, which is further converted to butyrylCoA via $\beta$-hydroxybutyryl-CoA and crotonyl-CoA [13].

Butyrate provides energy for colonic cell proliferation, but it does not have the same effect on CRC cell, because the energy of CRC cells is from glucose utilization and aerobic glycolysis due to Warburg effect [14]. Therefore, butyrate can regulate gene expression epigenetically via inhibiting class I histone deacetylase (HDAC), such as HDAC1 and HDAC3 [15]. Butyrate targets Fas and p21 in animal tumor models which have proapoptotic and antiproliferative activities, respectively [16].

Butyrate also serves as the agonist for certain G protein coupled receptors (GPR), including GPR43, GPR41, GPR109A, and Olfr78 [17]. GPR promotes naive CD4+ T cells to convert into immunosuppressive Tregs and upregulate the level of anti-inflammatory cytokine IL-10 and the pro-inflammatory cytokine IL-17 when it is activated in DCs. Macia L reported the absence of GPR accelerates colonic inflammation and the development of CRC in multiple experimental model systems [18]. Butyrate exerts the anti-proliferation and pro-apoptosis effects via signaling pathways in colonic epithelial tissues. Butyrate treatment (in $\mathrm{mM}$ concentrations) induces mothers against decapentaplegic homolog 3 (SMAD3) mRNA, which is a TGF- $\beta$ regulatory gene and can lead to the progression of cancer, and enhances the pro-apoptotic effects of TGF- $\beta$ signaling in the gut [19]. Butyrate can also lead to the fragmentation of genomic DNA, apoptosis and G1/G2 cell cycle arrest in CRC cells [20]. Butyrate actives Wnt pathway which is related to an up-regulation of the active $\beta$-catenin. $\beta$-catenin can be linked to one of two histone acetyltransferases, the cAMP-response element-binding protein (CREB) binding protein (CBP) or p300 [21]. Butyrate also influences barrier function [22]. In healthy conditions, normal gut microbiota can prevent the entry of pathogenic gut microbiota and cancerogenic material from intestinal epithelium [23]. According to some researches, SCFAs stimulate the expression of molecules which form the epithelial barrier and mucin production through activating 5 ' adenosine monophosphate-activated protein kinase (AMPK) and TLR4 pathway [24].

Other studies reported that butyrate may increase the susceptibility of tumorigenesis with gene modified [25].In a mouse model of adenomatous polyposis (APC) tumor suppressor gene mutation, butyrate reinforced the proliferation of colon epithelial cells and raised the number of tumors [26].

Propionate. Propionate is synthesized from phosphoenolpyruvate (PEP) via the succinate pathway or the acrylate pathway, in which propionate is produced by reducing lactate [13]. Propionate is mainly producted by Bacteroides spp., Phascolarctobacteriumsuccinatutens, Dialister spp., Veillonella spp., Megasphaeraelsdenii, Copr ococcuscatus, Salmonella spp., Roseburiainulinivorans, Ruminococcusobeum [12]. There are evidences about the over-expression of PRMT1 in the early stage of CRC, which contributes to the malignant characteristics of the progression of CRC. A trail demonstrated that propionate can down-regulate PRMT1 in the HCT116 cell line. According to siPRMT1 treatment, the reduction of PRMT1 will induce apoptosis by inhibiting phospho-p70 S6 kinase. However, the mechanisms of the association with propionate and PRMT1 regulation are currently unknown [27]. Propionate also possesses HDAC inhibitory effect. Propionate activates GPR41 and GPR43, the host will release satiety hormones and other metabolic and induce anti-inflammatory effects [28]. It is noteworthy that propionate inhibits the cytokine-induced expression of VCAM-1 and ICAM-1 and, as a consequence, mononuclear leukocytes adhere to the endothelial cells through inhibiting the activation of NF- $\kappa B$. Maybe the activity of PPAR $a$ can active the anti-inflammatory and anti-atherosclerotic activity of propionate [29].

\section{Polyphenolic Metabolites}

Polyphenols are another group of compounds found in plants. Polyphenolic metabolites have the abilities to repair damaged DNA, inhibit colon pathogens and regulate cell apoptosis [30]. Many researches indicated that the mechanism of these actions is mediated by modifying the synthesis of eicosanoids, down-regulating the inflammatory cascade, regulating DNA synthesis and inducing luminal detoxification enzymes [31]. These evidences indicate that polyphenols are beneficial to host health and prevent CRC.

Urolithins. Ellagic acid, which exerts in some berries and nuts, is a kind of polyphenol. It can be metabolized into urolithins with the activities of pro-estrogenic and anti-estrogenic by gut microbiota [32]. The anti-cancer effects of urolithins are related to multiple pathways, as it downregulates COX-2 to lower prostaglandin production, decreases the proliferation of cell and delays migration of cell and decreases activity of matrix metalloproteinas-9 (MMP-9). Mechanistic studies have suggested that urolithin A suppresses Wnt signaling and guard against cancer [33].The treatment of dietary submicromolar urolithin A has been reported to upregulate autophagy and suppress the development and metastasis of CRC SW620 cells. Subsequently, urolithin A stimulates cell death and exerts anti-metastatic effects by autophagy and caspases, which is revealed by Atg5siRNA and Z-VAD-FMK addition. These results provided original concepts to understand the antitumor role of urolithin A in CRC [34]. 
Equol. Gut microbiota metabolizes soya is oflavone daidzein, a polyphenol present in soybean into equol. Equol has the effect of estrogenic; it is also a valid antagonist of dihydrotestosterone in vivo. An analysis provided gender-based data to determine that soy consumption can reduce CRC risk by roughly 21 percent in women [35]. Another research found that equol inhibit the five kinds of CRC cell proliferation by its estrogenic activities and antioxidant activities, meanwhile, only different concentrations of ER $\beta$ agonist significantly inhibited the growth of CRC cells. Estrogen receptor inhibitor and ER $\alpha$ agonist did not present significant on the cell proliferation of CRC cells [36].

\section{Tryptophan Metabolites}

Tryptophan metabolite arise from protein catabolism, including indole, indole-3-aldehyde, indole-3-acetic acid, and indole-3-propionic acid. Indole-3-acrylic acid is generated by Peptostreptococcus. in colonic lumen [37]. This metabolite activates the antioxidant machinery in cells and is also an agonist for AhR, which exerts in colonic epithelial cells and suppresses inflammation and carcinogenesis [36]. The studies mentioned above suggest that indole-3-acrylic acid has the effect of anticancer.

\section{Conjugated Linoleic Acids (CLA)}

CLA belongs to the family of isomers of linoleic acid (LA). Lactobacillus and Bifidobacterium can convert LA to CLA. The CLA has the ability to control the morbidity of skin cancer, breast cancer, prostate cancer, and CRC in rodent models [38].CLA suppresses PI3K/Akt and ERK signaling cascade, consequently induces apoptosis and suppress cancer cell lines' cell cycle [39]. In previous studies, the anti-cancer mechanism of t10, c12-CLA over expressed a new proapoptotic protein, NAG-1 through AKT/GSK3b pathway and up-regulates ATF3 expression [40]. CLA also suppresses the growth of HT-29 and Caco-2 cells in a dose-dependent manner by upregulating the PPAR-c gene and inducing apoptosis as a ligand for the PPAR-c [41].

\section{Ferrichrome}

Ferrichrome is known as a small high affinity and iron-chelating molecules siderophore, which is created by Lactobacillus casei ATCC334; nowadays, it is regarded as an anti-cancer molecule. Ferrichrome induces apoptosis by activating the c-Jun N-terminal kinase (JNK)-DNA damage-inducible transcript 3 (DDIT3) pathways and upregulating the cleavage of poly adenosine diphosphate-ribose polymerase (PARP) in CRC cells [42]. Ferrichrome is safe for non-cancerous cells, as the growth of IEC-18 and primary cultured cells that belong to the mouse's small intestine are not influenced by it. Additionally, it is found that ferrichrome is equal to or even better than anticancer agents, such as 5-FU and cisplatin, in anti-tumor effect against CRC cells [43]. These results indicate that ferrichrome is a practical anti-cancer drug to inhibit the progression of CRC.

\section{Bacteriocins}

Bacteriocins, which are large molecular weight antimicrobial compounds produced by L. acidophilus, Bifdobacteriumbifdum NCFB 1454, L. plantarum, Lactococcus lactis, including bacterial peptides or proteins with antimicrobial properties $[44,45]$.

A series of researches indicate that bacteriocins are effective against food-borne pathogen. Such as bifdocin B, which B. bifdum NCFB 1454 secretes, protects host from several pathogenic bacteria, including Salmonella enterica ser. typhimurium SL1344 and E. coli C1845 [46]. Pediococcusacidilactici can generate Pediocin CP2. In undialys is $(1,600 \mathrm{AU} / \mathrm{ml})$ and dialysis $(800 \mathrm{AU} / \mathrm{ml})$ fractions of Pediocin CP2, the authors observed inhibition of human colon cancer cell (HT29) growth in 55 and $53.7 \%$, respectively [47].

As one of the natural AMPs, Nisin is generated by strains of Lactococcus lactis subsp. According to Knychalski B, nisin can significantly reduce mean tumor volumes no matter what concentrations [48]. Another study indicates that nisin A can reduce the expression of these MMPs and carcino-embryonic antigen (CEA) in CRC cells, compared to untreated cancer cells. Nisin A suppresses the metastatic process by down regulating CEA, CEAM6, MMP2F, MMP9F genes [49]. According to Ahmadi, nisin increases the bax/bcl-2 ratio in mRNA as well as protein levels, and thus causes the apoptosis on the SW480 cancer cell lines. These results implied that nisin possesses the cytotoxic effect on CRC cells and exerts the pro-apoptosis activity through intrinsic pathways [50]. However, additional investigations are required to find the mechanism why nisin has the anti-metastatic activity.

\section{Bacteria Components}

As mentioned above, gut microbiota metabolites have anti-cancer effects, and the components of gut microbiota can also trigger anti-tumor immune response. These components exist in the cell wall of gut microbiota. Here we will talk about lipopolysaccharide (LPS), lipoteichoic acid (LTA), $\beta$-glucans, and peptidoglycan.

\section{Lipopolysaccharide (LPS)}

LPS consists of Gram-negative bacteria (Escherichia coli or proteus species) cell wall. Several researches showed that LPS activates the toll-like receptor 4 (TLR4) which is one of pattern recognition receptors (PRRs) and exists on the surface of the host's cell. Hence, LPS activates immune T cell-mediated response to kill cancer cells [51]. However, other results demonstrated that LPS induce tumorigenes is due to the existence of the LPS receptor on colonocytes, which can prevent the cell from dying, upregulate the cellular immune response via TLR2, and consequently, activate following proinflammatory cytokine signaling [52]. 


\section{Lipoteichoic acid (LTA)}

LTA is regarded as the counterpart of LPS [53]. LTA can be found in Gram-positive bacteria (Bifidobacterium spp. or Lactobacilli). NO synthase induces cell death when the body is infected with the virus. LTA activates NO synthase by secreting TNF- $\alpha$, which up regulates the framework of vital phagocytes is receptors including TLRs and Fc $\gamma$ RIII [54]. This is very significant to initiate acquired immune responses, because the primary T cells differentiate the corresponding CD4+ Thelper subtypes when encountering antigens produced by APCs and the cytokines released in the acquired immunity [55].

\section{$\beta$-Glucans}

$\beta$-Glucans are biopolymers of D-glucose linked in the $\beta$ - $(1 \rightarrow 3)$ position with glucose side branches $(\beta$ - $(1 \rightarrow 6)$ linkage) of various sizes. $\beta$-Glucan guards the body against cancer cells by stimulating precursor cells in the bone marrow and inducing new immunocytes releasing to different lymphatic organs. $\beta$-Glucan also activates the killer cells through affecting the surface molecules in macrophages and NK cells [56]. These beneficial properties are vital when chemotherapy and radiotherapy have broken the anti-cancer immune system [57]. In the case of neutrophils, $\beta$-Glucan helps neutrophils identify cancer cells, trigger different death mechanisms, and then increases the results of monoclonal antibodies and vaccines [58].

\section{Peptidoglycan}

Another main component of the Gram-positive bacteria cell wall is peptidoglycan (approximately 90\%) [59]. Wang found that whole peptidoglycan (WPG) from the Lactobacillus paracasei subsp. paracasei M5 strain prevents the proliferation of HT-29 cell and induces apoptosis. The apoptosis property of WPG is mediated by up regulating proapoptotic genes, down regulating antiapoptotic genes and promoting the release of Cytochrome $\mathrm{C}$ $($ Cyto $\mathrm{C})$ in the mitochondria to the cytosol. Furthermore, the antiproliferative activity of WPG depends on dose [59].

\section{Conclusion}

Gut microbiota is a popular research topic these years because of their beneficial effects on human health. In this essay, we focus not merely on the antitumor functions of gut microbiota metabolites, but on the constituents of the bacterial cell wall. Gut microbiota metabolites can be classified into low molecular weight compounds like organic acids and macromolecular antibacterial compounds like bacteriocins. They have multiple effects, such as HDACi, and exhibit anti-inflammatory roles via signaling pathways, affecting barrier function, repairing damaged DNA, regulating cell apoptosis and destroying target cells. The components of the bacterial cell wall include LPS, LTA, $\beta$ glucans and peptidoglycan. The mechanisms of preventing CRC action include enhancing immune defense system and anti-proliferation of the CRC cell. In order to clear the intricate functions of gut microbiota, more studies are needed to investigate the specific mechanisms of the gut microbiota metabolites and constituents, and then find more beneficial substances associated with the gut microbiota. It is anticipated that the gut microbial metabolites will be applied in CRC treatment in the near future.

\section{Acknowledgments}

This work was supported by LIAONING S\&T project the Zhejiang Provincial Natural Science Foundation of China (No. LY20H160038); the Zhejiang Provincial Key R\&D Program of China (No. 2019C03018)

\section{Conflict of Interest}

The authors have no financial conflicts of interest to declare.

\section{References}

1. Siegel RL, Miller KD,Jemal A. 2020. Cancer statistics, 2020. CA Cancer J. Clin. 70: 7-30.

2. Lee C, Ho JW, Fong DY, Macfarlane DJ, Cerin E, Lee AM, et al. 2018. Dietary and physical activity interventions for colorectal cancer survivors: a randomized controlled trial. Sci. Rep. 8: 1-9.

3. Staley C, Weingarden AR, Khoruts A,Sadowsky MJ. 2017. Interaction of gut microbiota with bile acid metabolism and its influence on disease states. Appl. Microbiol. Biotechnol. 101: 47-64.

4. Yu J, Feng Q, Wong SH, Zhang D, yi Liang Q, Qin Y, et al. 2017. Metagenomic analysis of faecal microbiome as a tool towards targeted non-invasive biomarkers for colorectal cancer. Gut 66: 70-78.

5. Zhang Y-J, Li S, Gan R-Y, Zhou T, Xu D-P,Li H-B. 2015. Impacts of gut bacteria on human health and diseases. Int. J. Mol. Sci. 16: 7493-7519.

6. Knight R, Callewaert C, Marotz C, Hyde ER, Debelius JW, McDonald D, et al. 2017. The microbiome and human biology. Annu. Rev. Genomics Hum. Genet. 18: 65-86.

7. Magnúsdóttir S, Ravcheev D, de Crécy-Lagard V,Thiele I. 2015. Systematic genome assessment of B-vitamin biosynthesis suggests co-operation among gut microbes. Front. Genet. 6: 148.

8. Zitvogel L, Daillère R, Roberti MP, Routy B,Kroemer G. 2017. Anticancer effects of the microbiome and its products. Nat. Rev. Microbiol. 15: 465.

9. Farhana L, Banerjee HN, Verma M,Majumdar AP. 2018. Role of microbiome in carcinogenesis process and epigenetic regulation of colorectal cancer, pp. 35-55. Cancer Epigenetics for Precision Medicine, Ed. Springer,

10. van der Beek CM, Dejong CH, Troost FJ, Masclee AA,Lenaerts K. 2017. Role of short-chain fatty acids in colonic inflammation, carcinogenesis, and mucosal protection and healing. Nutr. Rev. 75: 286-305.

11. Ma Y, Hu M, Zhou L, Ling S, Li Y, Kong B, et al. 2018. Dietary fiber intake and risks of proximal and distal colon cancers: A metaanalysis. Medicine 97: e11678.

12. Louis P, Hold GL,Flint HJ. 2014. The gut microbiota, bacterial metabolites and colorectal cancer. Nat. Rev. Microbiol. 12: 661-672. 
13. Koh A, De Vadder F, Kovatcheva-Datchary P,Bäckhed F. 2016. From dietary fiber to host physiology: short-chain fatty acids as key bacterial metabolites. Cell 165: 1332-1345.

14. Donohoe DR, Garge N, Zhang X, Sun W, O'Connell TM, Bunger MK, et al. 2011. The microbiome and butyrate regulate energy metabolism and autophagy in the mammalian colon. Cell Metab. 13: 517-526.

15. Perego S, Sansoni V, Banfi G,Lombardi G. 2018. Sodium butyrate has anti-proliferative, pro-differentiating, and immunomodulatory effects in osteosarcoma cells and counteracts the TNFa-induced low-grade inflammation. Int. J. Immunopathol. Pharmacol. 31: 0394632017752240.

16. Zeng H, Taussig DP, Cheng W-H, Johnson LK,Hakkak R. 2017. Butyrate inhibits cancerous HCT116 colon cell proliferation but to a lesser extent in noncancerous NCM460 colon cells. Nutrients 9: 25.

17. Gonçalves P,Martel F. 2013. Butyrate and colorectal cancer: the role of butyrate transport. Curr. Drug Metab. 14: $994-1008$.

18. Macia L, Tan J, Vieira AT, Leach K, Stanley D, Luong S, et al. 2015. Metabolite-sensing receptors GPR43 and GPR109A facilitate dietary fibre-induced gut homeostasis through regulation of the inflammasome. Nat. Commun. 6: 6734.

19. Haque S,Morris JC. 2017. Transforming growth factor- $\beta$ : A therapeutic target for cancer. Hum. Vaccin. Immunother. 13: $1741-1750$.

20. Zeng H, Claycombe KJ,Reindl KM. 2015. Butyrate and deoxycholic acid play common and distinct roles in HCT116 human colon cell proliferation. J. Nutr. Biochem. 26: 1022-1028.

21. Bordonaro M,Lazarova DL. 2015. CREB-binding protein, p300, butyrate, and Wnt signaling in colorectal cancer. World J. Gastroenterol. 21: 8238.

22. Wu GD, Compher C, Chen EZ, Smith SA, Shah RD, Bittinger K, et al. 2016. Comparative metabolomics in vegans and omnivores reveal constraints on diet-dependent gut microbiota metabolite production. Gut 65: 63-72.

23. Yousefi B, Eslami M, Ghasemian A, Kokhaei P, Salek Farrokhi A,Darabi N. 2019. Probiotics importance and their immunomodulatory properties. J. Cell. Physiol. 234: 8008-8018.

24. Jacouton E, Chain F, Sokol H, Langella P,Bermudez-Humaran LG. 2017. Probiotic strain Lactobacillus casei BL23 prevents colitisassociated colorectal cancer. Front. Immunol. 8: 1553.

25. Belcheva A, Irrazabal T, Robertson SJ, Streutker C, Maughan H, Rubino S, et al. 2014. Gut microbial metabolism drives transformation of MSH2-deficient colon epithelial cells. Cell 158: 288-299.

26. Grivennikov SI, Wang K, Mucida D, Stewart CA, Schnabl B, Jauch D, et al. 2012. Adenoma-linked barrier defects and microbial products drive IL-23/IL-17-mediated tumour growth. Nature 491: 254-258.

27. Ryu TY, Kim K, Son M-Y, Min J-K, Kim J, Han T-S, et al. 2019. Downregulation of PRMT1, a histone arginine methyltransferase, by sodium propionate induces cell apoptosis in colon cancer. Oncol.Rep. 41: 1691-1699.

28. Kimura I, Inoue D, Maeda T, Hara T, Ichimura A, Miyauchi S, et al. 2011. Short-chain fatty acids and ketones directly regulate sympathetic nervous system via G protein-coupled receptor 41 (GPR41). Proc. Natl. Acad. Sci. USA 108: 8030-8035.

29. Orlando A, Messa C, Linsalata M, Cavallini A,Russo F. 2009. Effects of Lactobacillus rhamnosus GG on proliferation and polyamine metabolism in HGC-27 human gastric and DLD-1 colonic cancer cell lines. Immunopharmacol. Immunotoxicol. 31: 108-116.

30. Miene C, Weise A,Glei M. 2011. Impact of polyphenol metabolites produced by colonic microbiota on expression of COX-2 and GSTT2 in human colon cells (LT97). Nutr. Cancer 63: 653-662.

31. Cardona F, Andrés-Lacueva C, Tulipani S, Tinahones FJ,Queipo-Ortuño MI. 2013. Benefits of polyphenols on gut microbiota and implications in human health. J. Nutr. Biochem. 24: 1415-1422.

32. Bultman SJ. 2016. Presented at the Seminars in oncology.

33. Gonzalez-Sarrias A, Giménez-Bastida JA, Núñez-Sánchez MÁ, Larrosa M, García-Conesa MT, Tomás-Barberán FA, et al. 2014. Phase-II metabolism limits the antiproliferative activity of urolithins in human colon cancer cells. Eur. J. Nutr. 53: 853-864.

34. Zhao W, Shi F, Guo Z, Zhao J, Song X,Yang H. 2018. Metabolite of ellagitannins, urolithin A induces autophagy and inhibits metastasis in human sw620 colorectal cancer cells. Mol. Carcinog. 57: 193-200.

35. Yan L, Spitznagel EL,Bosland MC. 2010. Soy consumption and colorectal cancer risk in humans: a meta-analysis. Cancer Epidemiol. Biomarkers Prev. 19: 148-158.

36. Cai Y, Zhang H, Niu W, Zou Y,Ma D. 2017. Effects of equol on colon cancer cell proliferation. Beijing Da Xue Xue Bao. 49: $383-387$.

37. Wlodarska M, Luo C, Kolde R, d'Hennezel E, Annand JW, Heim CE, et al. 2017. Indoleacrylic acid produced by commensal peptostreptococcus species suppresses inflammation. Cell Host Microbe. 22: 25-37. e26.

38. Dilzer A,Park Y. 2012. Implication of conjugated linoleic acid (CLA) in human health. Crit Rev. Food Sci. Nutr. 52: 488-513.

39. Kim EJ, Kang I-J, Cho HJ, Kim WK, Ha Y-L,Park JHY. 2003. Conjugated linoleic acid downregulates insulin-like growth factor-I receptor levels in HT-29 human colon cancer cells. J. Nutr. 133: 2675-2681.

40. Kim K-J, Lee J, Park Y,Lee S-H. 2015. ATF3 mediates anti-cancer activity of trans-10, cis-12-conjugated linoleic acid in human colon cancer cells. Biomol. Ther 23: 134-140.

41. Kuniyasu H, Yoshida K, Sasaki T, Sasahira T, Fujii K,Ohmori H. 2006. Conjugated linoleic acid inhibits peritoneal metastasis in human gastrointestinal cancer cells. Int. J. Cancer 118: 571-576.

42. Ijiri M, Fujiya M, Konishi H, Tanaka H, Ueno N, Kashima S, et al. 2017. Ferrichrome identified from Lactobacillus casei ATCC334 induces apoptosis through its iron-binding site in gastric cancer cells. Tumor Biol. 39: 1010428317711311.

43. Konishi H, Fujiya M, Tanaka H, Ueno N, Moriichi K, Sasajima J, et al. 2016. Probiotic-derived ferrichrome inhibits colon cancer progression via JNK-mediated apoptosis. Nat. Commun. 7: 1-12.

44. Karpiński TM,Szkaradkiewicz AK. 2013. Characteristic of bacteriocines and their application. Pol. J. Microbiol. 62: 223-235.

45. Nielsen DS, Cho G-S, Hanak A, Huch M, Franz CM,Arneborg N. 2010. The effect of bacteriocin-producing Lactobacillus plantarum strains on the intracellular $\mathrm{pH}$ of sessile and planktonic Listeria monocytogenes single cells. Int. J. Food Microbiol. 141: S53-S59.

46. Lievin V, Peiffer I, Hudault S, Rochat F, Brassart D, Neeser J, et al. 2000. Bifidobacterium strains from resident infant human gastrointestinal microflora exert antimicrobial activity. Gut 47: 646-652.

47. Balgir PP, Bhatia P,Kaur B. 2010. Sequence analysis and homology based modeling to assess structure-function relationship of pediocin CP2 of Pediococcus acidilactici MTCC 5101. IJBT 9: 431-434.

48. Knychalski B,Łukieńczuk T. 2012. The evaluation of diagnostic value of the tumor markers: CCSA-2 and CEA in colorectal cancer. Pol. Przegl. Chir. 84: 86-92

49. Norouzi Z, Salimi A, Halabian R,Fahimi H. 2018. Nisin, a potent bacteriocin and anti-bacterial peptide, attenuates expression of metastatic genes in colorectal cancer cell lines. J. Microb. Pathog. 123: 183-189.

50. Ahmadi S, Ghollasi M,Hosseini HMJMp. 2017. The apoptotic impact of nisin as a potent bacteriocin on the colon cancer cells. Microb. Pathog. 111: 193-197.

51. Paulos CM, Wrzesinski C, Kaiser A, Hinrichs CS, Chieppa M, Cassard L, et al. 2007. Microbial translocation augments the function of adoptively transferred self/tumor-specific CD8+ T cells via TLR4 signaling. J. Clin. Invest 117: 2197-2204.

52. Ryu TY, Kim K, Son M-Y, Min J-K, Kim J, Han T-S, et al. 2019. Downregulation of PRMT1, a histone arginine methyltransferase, by sodium propionate induces cell apoptosis in colon cancer. Oncol. Rep. 41: 1691-1699.

53. Wang SM, Zhang LW, Gu W, Xue CH, Zhang YC, et al. 2012. Screening for antiproliferative effect of lactobacillus strains against colon cancer HT-29 cells. Adv. Mater. Res. 573: 1039-1043. 
54. Dongarrà ML, Rizzello V, Muccio L, Fries W, Cascio A, Bonaccorsi I, et al. 2013. Mucosal immunology and probiotics. Curr. Allergy Asthma Rep. 13: 19-26.

55. Kim H-J, Kim Y-J, Lee S-H, Yu J, Jeong SK,Hong S-J. 2014. Effects of Lactobacillus rhamnosus on allergic march model by suppressing Th2, Th17, and TSLP responses via CD4 $4^{+} \mathrm{CD} 25^{+}$Foxp3 $^{+}$Tregs. Clin. Immunol. 153: 178-186.

56. Volman JJ, Ramakers JD, Plat J. 2008. Dietary modulation of immune function by $\beta$-glucans. Physiol. Behav. 94: 276-284.

57. Hong F, Hansen RD, Yan J, Allendorf DJ, Baran JT, Ostroff GR, et al. 2003. $\beta$-Glucan functions as an adjuvant for monoclonal antibody immunotherapy by recruiting tumoricidal granulocytes as killer cells. Cancer Res. 63: 9023-9031.

58. Artur Javmen, Aušra Nemeikaitè-Čènienè, Maksim Bratchikov, Saulius Grigiškis, Fortūnatas Grigas, Irena Jonauskienė, et al. 2015. $\beta$-Glucan from Saccharomyces cerevisiae induces IFN- $\gamma$ production in vivo in BALB/c mice. In Vivo. 29: 359-363.

59. Wang S, Han X, Zhang L, Zhang Y, Li H,Jiao Y. 2018. Whole peptidoglycan extracts from the lactobacillus paracasei subsp. Paracasei M5 strain exert anticancer activity in vitro. Biomed. Res. Int. 2018: 2871710.

60. Rong J, Liu S, Hu C,Liu C. 2019. Single probiotic supplement suppresses colitis-associated colorectal tumorigenesis by modulating inflammatory development and microbial homeostasis. J. Gastroenterol. Hepatol. 34: 1182-1192.

61. Ghoneum,Mamdooh. 2014. Apoptotic effect of a novel kefir product, PFT, on multidrug-resistant myeloid leukemia cells via a holepiercing mechanism. Int. J. Oncol. 44: 830-837.

62. Yousef N, Babak H, Minoo H, Norhafizah A,Ahmad YK. 2015. The prophylactic effect of probiotic Enterococcus lactis IW5 against different human cancer cells. Front. Microbiol. 6: 1317.

63. Orlando A, Refolo M, Messa C, Amati L, Lavermicocca P, Guerra V, et al. 2012. Antiproliferative and proapoptotic effects of viable or heat-killed Lactobacillus paracasei IMPC2. 1 and Lactobacillus rhamnosus GG in HGC-27 gastric and DLD-1 colon cell lines. Nutr. Cancer 64: 1103-1111.

64. Al-Busaidi IS, Bailey T, Dobbs B, Eglinton TW, Wakeman CJ,Frizelle FA. 2019. Complete resection of colorectal cancer with ovarian metastases combined with chemotherapy is associated with improved survival. ANZ J. Surg. 89: 1091-1096.

65. Chung I-C, OuYang C-N, Yuan S-N, Lin H-C, Huang K-Y, Wu P-S, et al. 2019. Pretreatment with a heat-killed probiotic modulates the NLRP3 inflammasome and attenuates colitis-associated colorectal cancer in mice. Nutrients 11: 516.

66. Agah S, Alizadeh AM, Mosavi M, Ranji P, Khavari-Daneshvar H, Ghasemian F, et al. 2019. More protection of Lactobacillus acidophilus than Bifidobacterium bifidum probiotics on azoxymethane-induced mouse colon cancer. Probiotics Antimicrob. Proteins 11: 857-864.

67. Aisu N, Tanimura S, Yamashita Y, Yamashita K, Maki K, Yoshida Y, et al. 2015. Impact of perioperative probiotic treatment for surgical site infections in patients with colorectal cancer. Exp. Ther. Med. 10: 966-972.

68. Theodoropoulos GE, Memos NA, Peitsidou K, Karantanos T, Spyropoulos BG,Zografos G. 2016. Synbiotics and gastrointestinal function-related quality of life after elective colorectal cancer resection. Ann. Gastroenterol. 29: 56-62.

69. Consoli MLD, da Silva RS, Nicoli JR, Bruña-Romero O, da Silva RG, de Vasconcelos Generoso S, et al. 2016. Randomized clinical trial: impact of oral administration of Saccharomyces boulardii on gene expression of intestinal cytokines in patients undergoing colon resection. JPEN J. Parenter Enteral Nutr. 40: 1114-1121.

70. Hibberd AA, Lyra A, Ouwehand AC, Rolny P, Lindegren H, Cedgård L, et al. 2017. Intestinal microbiota is altered in patients with colon cancer and modified by probiotic intervention. BMJ Open Gastroenterol. 4: e000145.

71. Flesch AT, Tonial ST, Contu PDC, Damin DC. 2017. Perioperative synbiotics administration decreases postoperative infections in patients with colorectal cancer: a randomized, double-blind clinical trial. Randomized Controlled Trial 44: 567-573. 